\title{
Long-term Unit Commitment Combined Optimization Method of Equilibrium Generation Scheduling and Load Ratio
}

\author{
Haihua Cheng ${ }^{\mathrm{a}}$, Yaxian Zheng ${ }^{\mathrm{b}}$, Bike Xue ${ }^{\mathrm{c}}$, Jian Gen ${ }^{\mathrm{d}}$, Shuai Cao ${ }^{\mathrm{e}}$ \\ China Electric Power Research Institute Nanjing Branch, \\ Nanjing, China \\ achenghaihua@epri.sgcc.com.cn, b zhengyaxian@epri.sgcc.com.cn, \\ cxuebike@epri.sgcc.com.cn, ${ }^{\mathrm{d}}$ genjian@epri.sgcc.com.cn, \\ esunever@qq.com
}

\begin{abstract}
The article proposed a combination optimization method of load ratio and equilibrium power generation scheduling in long-term unit commitment base on the traditional long-term unit commitment method, which can satisfy the equilibrium generation scheduling needs, and improve the unit load rate as far as possible at the same time. The method can reduce the unit pollution emissions. The method solves the problem of load rate cannot be optimized in traditional method of long-term combined unit. The article proposed two different optimization methods, and used the real provincial data in the example. The example shows that, the combined optimization method can not only satisfy the equilibrium generation scheduling needs, but also improve the load rate of the units as far as possible, the example proves the validity and practicability of the proposed method.
\end{abstract}

Keywords-long-term unit commitment; equilibrium generation scheduling; combined optimization

\section{INTRODUCTION}

Equilibrium generation scheduling is currently the main scheduling model, the core objective is to ensure that the annual contracts synchronous execution of power plants. The dispatching departments usually divide annual plan into monthly plan, and divide the monthly plan into daily plan, and then execution by schedule ${ }^{[1]}$. In the long-term unit commitment, the constraints of the power and energy balance, power system security, unit ramping, unit output limitation should be taken into consideration $^{[1][2][3]}$, the optimization model is very complex, it is difficult to consider the unit load rate optimization. But the load rate levels often have influence on the pollution of units and the energy cost. With the unit load rate levels increase, fuel costs and pollution emissions will be reduced ${ }^{[4]}$, but generally unit's output power is not arranged to maximum, because if the unit's output power reaches the maximum, the power system reservation may be reduced. So how to satisfy the energy balance constraint, power balance constraints, system reservation constraints, network security constraint, to achieve ideal load rate and equilibrium power generation scheduling, is a difficult problem to be solved.

This paper proposed a combination optimization method of load ratio and equilibrium power generation scheduling in long-term unit commitment, to meet the needs of equilibrium power generation scheduling, and improve the unit load rate as far as possible at the same time. The method can reduce pollution emissions and improve scheduling management level.

\section{TRADITIONAL LONG-TERM UNIT COMMITMENT}

In this paper, the case is: the annual plan is divided into monthly plan, how to arrange daily unit status (running or stop) and unit's daily energy plan to ensure equilibrium generation scheduling.

\section{A. Equilibrium Generation Scheduling Optimization} Objective Model

$\min f=\sum_{i=1}^{N} \frac{\left|\sum_{t=1}^{T} E(i, t)-E_{g}(i)\right|}{E_{g}(i)}$

$E(i, t)$ : The energy of unit $i$ in period $t$, it is an optimization variable ;

$E_{g}(i)$ : The monthly energy plan of the unit $i$;

$f$ : The deviation of completion progress;

\section{B. System Constraint}

- Power balance constraint:

$\sum_{i}^{I} p_{i}(t)=p_{d}(t) \quad t=1,2, \ldots . . T$

$p_{i}(t)$ : The unit output of unit $i$ in period $t$, it is an optimization variable;

$p_{d}(t)$ : The forcasting power load in period ${ }^{t}$;

- Energy balance constranit:

$\sum_{i}^{I} E(i, t)=E_{d}(t) \quad t=1,2, \ldots . . T$

$E_{d}(t)$ : The forcasting energy load in period $t$;

- Association constraint of power and energy: 
$E(i, t)=p_{i}(t) * R(i, t) * \operatorname{Pr} d \operatorname{Min}(t) / 60$

$\operatorname{Pr} d \operatorname{Min}(t)$ : The minutes of period $t$;

$R(i, t)$ : The load ratio of unit $i$ in period $t$, it is an optimization variable;

- System reservation constraint:

$\sum_{i=1}^{I}\left(p_{\max }(i, t) * u_{i}(t)-p_{i}(t)\right) \geq R_{u p}(t)$

$\sum_{i=1}^{I}\left(p_{i}(t)-p_{\min }(i, t) * u_{i}(t)\right) \geq R_{\text {down }}(t)$

$p_{\max }(i, t)$ : The maximum output power of unit $i$;

$p_{\min }(i, t)$ : The minimum output power of unit $i$;

$R_{u p}(t)$ : The up value of spinning reservation of period $t$;

$R_{\text {down }}(t)$ : The down value of spinning reservation of period $t$;

$u_{i}(t)$ : The status of unit $i, 0$ replace stop, 1 replace running;

- Unit output limitation constraint:

$\left.p_{\text {min }}(i, t) * u_{i}(t) \leq p_{i}(t)\right) \leq p_{\max }(i, t) * u_{i}(t)$

- The minimum running time constranit and the minimum stop time constraint:

$\left\{\begin{array}{l}u_{i}(t)=1,1 \leq x_{i}(\mathrm{t}) \leq \overline{\tau_{i}} \\ u_{i}(t)=-1,-\underline{\tau}_{i} \leq x_{i}(\mathrm{t}) \leq-1\end{array}\right.$

$\bar{\tau}_{i}$ : The minimum running time of unit $i$;

$\underline{\tau_{i}}$ : The minimum stop time of unit $i$;

- Unit ramp constraint:

$-\Delta(i, t) \leq p_{i}(t)-p_{i}(t-1) \leq \Delta(i, t)$

$\Delta(i, t)$ : The maximum ouput can add and subtract of unit $i$ in period $t$;

- Network security constraint:

$P_{i j}(t) \leq \overline{P_{i j}}$

$P_{i j}(t)$ : The power folw in branch ${ }^{i j}$ in period $t$;

$\overline{P_{i j}}$ : The upper value of power flow in in branch $i j$ in period $t$

With the optimization goal of equilibrium generation scheduling, considering the power balance, energy balance, system reservation, network security constraints and so on, it use complex commercial algorithm software, mixed integer programming optimization method, to obtain optimal results.

\section{COMBINATION OptimizATION MODEL}

How to meet the needs of equilibrium power generation scheduling, and improve the unit load rate as far as possible at the same time, there are two different optimization modeling methods. One is add mandatory constraints of load ratio. The second is joint optimization of load ratio and equilibrium generation scheduling.

\section{A. The First Method: Mandatory Constraints}

Base on the traditional long-term unit commitment model, add the constraint of load ratio as follows:

$$
\begin{gathered}
R_{\text {min }}(i, t) \leq R(i, t) \leq R_{\max }(i, t) \\
R_{\min }(i, t) \text { : The low limitation of load ratio; } \\
R_{\max }(i, t) \text { : The up limitation of load ratio; }
\end{gathered}
$$

\section{B. The second Method: Joint Optimization}

Use the multi-objective optimization method to joint optimization of the two optimization objectives. First, we define the load rate deviation costs; second, we can define the two optimization objectives, one is equilibrium generation scheduling, the other is to minimize load rate deviation costs. Finally, we can joint optimization.

- Load rate deviation costs

We define the load rate deviation costs. There is a deviation between the unit's load ratio and the ideal load ratio (or ideal load ratio interval), the deviation have a corresponding bias costs. The method allows you to set different ideal interval of load ratio for different types of units, for less-polluting emissions units can be set to a higher load ratio.

$R(i, t)-R^{\prime} \quad(i, t)=\Delta^{+}{ }_{R}(i, t)-\Delta^{-}{ }_{R}(i, t)$

RatioBia $=\left(\Delta^{+}{ }_{R}(i, t)+\Delta^{-}{ }_{R}(i, t)\right) * \operatorname{Inc} \cos t(i, t)$

$R^{\prime} \quad(i, t)$ : The ideal load ratio of unit $i$ in period $t$;

$R \quad(i, t)$ : The load ratio of unit $i$ in period $t$;

$\Delta^{+}{ }_{R}(i, t) 、 \Delta^{-}{ }_{R}(i, t)$ : The positive and negative deviations of unit $i$ in period $t$;

Inc $\cos t(i, t)$ : The virtual costs of deviation between the unit's load ratio and the ideal load ratio for unit $i$ in period $t$;

RatioBia : The load rate deviation costs.

- Joint optimization model of the two optimization objectives

Using the joint optimization method to achieve equilibrium generation scheduling and load ratio optimization target joint optimization. First, through optimization with the single objective: equilibrium generation scheduling to obtain the maximum load rate deviation costs $B$. Then reduce the maximum load rate deviation costs, and form constraint about load rate deviation costs, add the constraint into the optimization calculations.

RatioBia $\leq B^{*}(1-$ factor $)$

$0 \leq$ factor $\leq 1$

$B$ : The maximum load rate deviation costs; 
factor : The reduce factor ;

- Joint optimization calculation

The unit load rate deviation cost constraints (Equation 14) is added into the optimization algorithm to optimize re-calculated, it can obtain joint optimization result of equilibrium generation scheduling and load ratio. You can adjust the reduce factor $B$, re-calculate, and get different joint optimization result. The decision-makers can choose the best optimization result.

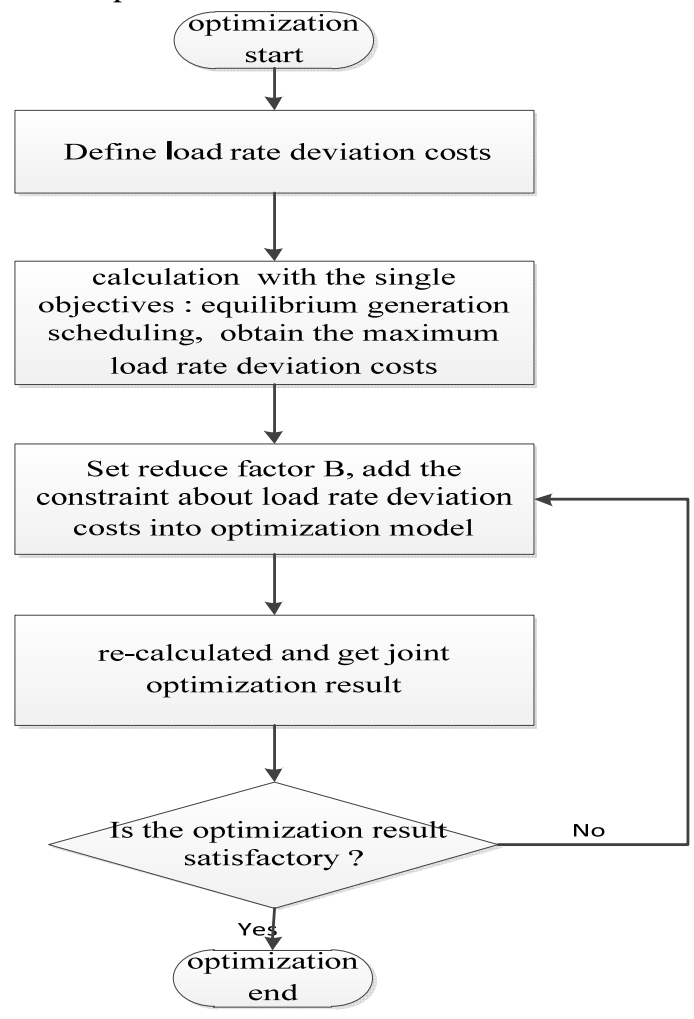

Figure 1. The flowchart of joint optimization

\section{EXAMPLE}

In this example, we use provincial actual data to test the optimization model, There are 46 plants (149 units ) to optimize the daily energy plan, the daily status (running or stop) of units in one month,. The optimization objective is equilibrium power generation scheduling. The ideal load ratio interval is $[0.65,0.80]$. Pick two points to optimize every day, one is peak load point, the other is lowest load point. So the unit commitment result can meet the daily peak load and lowest load demand. If the unit commitment result can meet the network security constraints at these two points every day, so unit commitment result can meet the network security constraints in the whole month.

\section{A. Optimization Result for the First Method}

In the first method, base on the traditional long-term unit commitment model, add the mandatory constraint of load ratio, optimization result is as follows:
TABLE I. UNIT COMMITMENT RESULT FOR MANDATORY CONSTRAINTS MODEL

\begin{tabular}{|c|c|c|c|c|}
\hline \multicolumn{1}{|c|}{$\begin{array}{c}\text { Plant's } \\
\text { name }\end{array}$} & $\begin{array}{c}\text { Monthly } \\
\text { energy } \\
\text { plan }\end{array}$ & $\begin{array}{c}\text { Optimization } \\
\text { result for } \\
\text { monthly plan }\end{array}$ & $\begin{array}{c}\text { Completion } \\
\text { progress of } \\
\text { monthly plan }\end{array}$ & $\begin{array}{c}\text { Uniation } \\
\text { of } \\
\text { completion } \\
\text { progress }\end{array}$ \\
\hline Plant-1 & 1176000 & 1094400 & 0.931 & 0.069 \\
\hline Plant-2 & 835000 & 785664 & 0.941 & 0.059 \\
\hline Plant-3 & 1157000 & 1089216 & 0.941 & 0.059 \\
\hline Plant-4 & 1138000 & 1071360 & 0.941 & 0.059 \\
\hline Plant-5 & 269000 & 253440 & 0.942 & 0.058 \\
\hline Plant-6 & 34000 & 34000 & 1.000 & 0.000 \\
\hline Plant-7 & 188000 & 188000 & 1.000 & 0.000 \\
\hline Plant-8 & 191000 & 191000 & 1.000 & 0.000 \\
\hline Plant-9 & 145000 & 145000 & 1.000 & 0.000 \\
\hline Plant-10 & 160000 & 160000 & 1.000 & 0.000 \\
\hline$\ldots \ldots$ & $\ldots \ldots$. & $\ldots \ldots$ & $\ldots \ldots$ & $\ldots \ldots$ \\
\hline Plant -41 & 470000 & 488800 & 1.040 & 0.040 \\
\hline Plant -42 & 449000 & 466960 & 1.040 & 0.040 \\
\hline Plant -43 & 509000 & 529360 & 1.040 & 0.040 \\
\hline Plant -44 & 630000 & 655200 & 1.040 & 0.040 \\
\hline Plant -45 & 1187000 & 1265664 & 1.066 & 0.066 \\
\hline Plant -46 & 680000 & 725328 & 1.067 & 0.67 \\
\hline
\end{tabular}

The deviation of completion progress

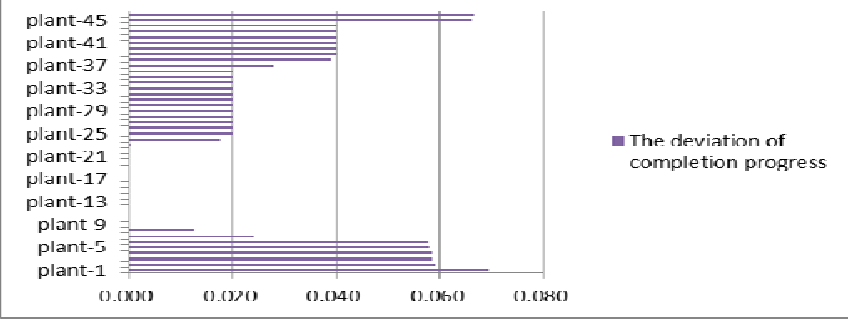

Figure 2. Unit commitment result for mandatory constraints model

Analyze: In the optimization result, the max deviation of completion progress of units reach $6.9 \%$, because the mandatory constraints is added into the optimization model. So this method can't meet the production need, the optimization result is not satisfactory.

\section{B. Optimization Result for the Second Method}

In the second method, use the multi-objective optimization method to joint optimization of the two optimization objectives. First, optimize with the single objectives: equilibrium generation scheduling, then get the maximum load rate deviation costs $B$. Second, set the reduce factor $=0.1 、 0.3 、 0.5 、 0.8 、 0.9 、 0.99$ and 1.0 , re-calculate and get different joint optimization results with different reduce factor, the optimization results as follows: 
TABLE II. DIFFERENT OPTIMIZATION RESULTS FOR JOINT OPTIMIZATION

\begin{tabular}{|c|c|c|c|c|}
\hline \multirow{2}{*}{$\begin{array}{c}\text { Different reduce } \\
\text { factor }\end{array}$} & \multicolumn{2}{|c|}{$\begin{array}{c}\text { The deviation of } \\
\text { completion progress }\end{array}$} & \multicolumn{2}{c|}{ Load rate of units } \\
\cline { 2 - 5 } & $\begin{array}{c}\text { Maxinum } \\
\text { value }\end{array}$ & $\begin{array}{c}\text { Average } \\
\text { value }\end{array}$ & $\begin{array}{c}\text { Maxinum } \\
\text { value }\end{array}$ & $\begin{array}{c}\text { Minimum } \\
\text { value }\end{array}$ \\
\hline Reduce factor=0 & 0.0112 & 0.00042 & 0.85 & 0.611 \\
\hline Reduce factor=0.1 & 0.0112 & 0.00042 & 0.85 & 0.6223 \\
\hline Reduce factor=0.3 & 0.0112 & 0.00042 & 0.85 & 0.6223 \\
\hline Reduce factor=0.5 & 0.0112 & 0.00042 & 0.85 & 0.6308 \\
\hline Reduce factor=0.8 & 0.0112 & 0.00042 & 0.85 & 0.6308 \\
\hline Reduce factor=0.9 & 0.02 & 0.0054 & 0.85 & 0.6498 \\
\hline Reduce factor=0.99 & 0.05 & 0.0209 & 0.82 & 0.65 \\
\hline Reduce factor=1 & 0.0694 & 0.0238 & 0.8 & 0.65 \\
\hline
\end{tabular}

Analyze: with the reduce factor increases, the permitted deviation cost of load ratio decreases, the load rates of units gradually go into the ideal load rate interval $[0.65,0.80]$. When the reduce factor increase from 0.1 to 0.9 , the minimum value of load rate gradually increases from 0.611 to 0.6496 , but the average deviation of completion progress increases at the same time. When the reduce factor equals 1 , the load rates of all units go into the ideal rate interval $[0.65,0.80]$, but the average value of deviation of completion progress reaches 0.0238 , the maximum value of deviation of completion progress reaches 0.0694 . The dicision maker can choose one optimization result as the optimal solution according to the actual situation. For example, if the maximum permissible deviation of monthly completion progress is $2 \%$, you can choose the optimization result with reduce fator 0.9 as the optimal solution .

\section{SUMMARY}

This paper proposed a combination optimization method of load ratio and equilibrium generation scheduling in long-term unit commitment base on the traditional long-term unit commitment method, which can satisfy the equilibrium generation scheduling needs, and improve the unit load rate as far as possible at the same time. The method can reduce the unit pollution emissions. The method solves the problem of load rate cannot be optimized in traditional method of long-term combined unit. At the last, use provincial data examples to demonstrate the effectiveness and practicality of the method.

\section{ACKNOWLEDGMENT}

The work is supported by projects as follows: 1.The science and technology project of State Grid Corporation of China (DZN17201400039); 2.The science and technology project of North China Power Grid of China (DZN11201404007); 3.Natural Science Foundation Project (51477157); 4. China Electric Power Research Institute Project (DZ83-14-003).

\section{REFERENCES}

[1] Li Lili, Gen Jian, Yao Jianguo, et al. Model and Algorithm for Security Constrained Economical Dispatch in Equilibrium Power Generation Dispatch Mode. Automation of Electric Power Systems, 2010, 34(15): P23-27.

[2] Li Lili, Guan Yibin, Gen Jian, Modeling And Solving for Monthly Security Constrained Unit Commitment Problem. Automation of Electric Power Systems, 2011, 35(12): P27-31.

[3] Guan Yibin, Wang Gang, Li Qiang, Design of Monthly Unit Commitment for Jiangsu Power Grid, Automation of Electric Power Systems, 2012, 36(13): P106-109.

[4] TENG Xiaobi, Li JiHong, WU Zhen, JIANG Wei, New Mode of energy-conservation dispatching based on thermal unit cyclic operation and its benefit analysis, Electric Power , 2010, 43(9): P19-23. 